\title{
Characteristic analysis of gas \& solid phase flow in oil shale pyrolysis circulating fluidized bed
}

\author{
Mingshu Chi ${ }^{*}$, Qing Wang ${ }^{2}$, Hongpeng $\mathrm{Liu}^{2}$, Zhichao Wang ${ }^{2}$, Qi Liu \\ ${ }^{1}$ School of Energy Power and Mechanical Engineering, North China Electric Power University, Beijing 102206, China \\ ${ }^{2}$ Engineering research Center of Oil Shale Comprehensive Utilization, Ministry of Education, Northeast Electric Power \\ University, Jilin 132012, China
}

Corresponding Author Email: cms20062006@163.com

https://doi.org/10.18280/ijht.360121

Received: 2 September 2017

Accepted: 17 October 2017

\author{
Keywords: \\ gas \& solid phase flow, oil shale, $C F B$, \\ computational fluid mechanics of \\ particles.
}

\begin{abstract}
Emissions from common oil shale extraction equipment contain many small-size oil shale particles unprocessed. Pyrolyzing oil shale by using CFB (circulating fluidized bed) can solve this problem well. To investigate kinetic characteristics of oil shale particles in CFB, we studied the difference in fluidization characteristic of oil shale particles between various mainflow air intakes by simulating the fluidization process based on computational fluid mechanics of particles. It turned out that: when airflow pushes particles a spherical "bubble" zone forms, and when the bubble bursts the horizontal size is subtly affected by air intake; increasing air intake can accelerate oil shale particles fluidization and improve the cyclone separator outlet air velocity.
\end{abstract}

\section{INTRODUCTION}

Oil is in greater demand with the rapid development of Chinese social economy but China is poor in petroleum resources, so it is hard to satisfy the increasing demand for oil consumption. Oil shale [1] is an excellent raw material of a liquid substitute for oil, cheap, in huge reserves, with high oil content [2]. A common industrial means to extract oils from oil shale is pyrolysis [3, 4]. For example, Kiviter furnace from Estonia [5], Petrosix furnace from Brazil [6] and Fushun furnace from China [7] take lump coal or formed coal as the raw material and discard unexploited small-size oil shale particles as gangue, causing a great waste of resources and environmental pollution [8]. Thus, how to further extract oil from these unprocessed small-size oil shale particles becomes a hot issue in the petroleum industry. Researchers all over the world have done extensive researches, expecting to develop a new technology of fine grainy oil shale pyrolysis oil extraction with low dust content and available for long-time running and to realize the efficient pyrolysis and clean refining of oil shale. CFB (circulating fluidized bed) features complete reaction [912] and outlet reactants reacting repeatedly, so pyrolyzing oil shale particles by using CFB can solve the incomplete processing of small-size oil shale particles. Normally, in this way, the exterior of pyrolysis CFB is entirely heated so that temperature distribution is even. Therefore, the fluidization degree of oil shale particles in CFB is one of the main factors influencing the pyrolysis process. Taking cold-state oil shale $\mathrm{CFB}$ as the research object, we studied the fluidization characteristic of oil shale in CFB based on a computational particle mechanics theoretical model.

\section{NUMERICAL METHODS}

For gas \& solid phase flow problems, the traditional CFD method with limitations can hardly apply to lots of particles.
However, cpfd can calculate a great number of multi-scale particles. When processing particle fluidization, cpfd is faster in calculation and its calculation result is similar to traditional cfd.

CPFD numerical method is an efficient calculation method, proposed by Dr. Dale M. Snider [13], to solve the threedimensional motion of particles in fluid based on EulerLagrange equation. Different from other multiphase flow numerical methods, CPFD sets forth the "granulosity" concept. In the process of solution, a number of particles with similar features are packed forming computational particles, which gravity, friction and collision force act on in a flow field. The gas-phase motion and particle-phase motion are solved based on their governing equations respectively. In this process, governing equations [14] corresponding to gas are:

$$
\begin{aligned}
& \frac{\partial}{\partial t}\left(\rho_{g} \theta_{g}\right)+\nabla \bullet\left(\rho_{g} \theta_{g} v_{g}\right)=S_{g} \\
& \frac{\partial}{\partial t}\left(\rho_{g} \theta_{g} v_{g}\right)+\nabla \bullet\left(\rho_{g} \theta_{g} v_{g}\right)=-\nabla P+\nabla \bullet \theta_{g} \tau_{g}+\rho_{g} \theta_{g} g-F
\end{aligned}
$$

where, $\theta_{g}$ is volume fraction of the gas phase; $\rho_{g}, v_{g}$ are density and flow of gas; $\tau_{g}$ is stress tensor of the gas phase; $S g$ is gas source item; $P$ is gas pressure; $g$ is acceleration of gravity; and $F$ is viscous force between two phases:

$F=\iint f m\left(4.5 \frac{\mu_{g}}{\rho_{p} r_{p}^{2}} f_{b}\left(v_{g}-v_{p}\right)-\frac{\nabla P}{\rho_{p}}\right) d m d v$

where, $\mu_{g}$ is kinetic viscosity of the gas phase; $r_{p}$ is radius of a particle, $v_{p}$ is velocity of the particle phase; $\rho_{p}$ is density of the particle phase, and $f$ is PDF (probability distribution function).

The drag force model involved in this paper contains Wen$\mathrm{Yu} /$ Ergun $[15,16]$. It is obtained through linear transformation 
of Wen-Yu model and Ergun model. Thus, the coefficient $f_{b}$ depending on drag force model is expressed as follows:

$\left\{\begin{array}{l}f_{b}=f_{w}, \theta_{p}<0.75 \theta_{c p} \\ f_{b}=f_{w}+\frac{\theta_{p}-0.75 \theta_{c p}}{0.1 \theta_{c p}}\left(f_{e}-f_{w}\right), 0.75 \theta_{c p} \leq \theta_{p} \leq 0.85 \theta_{c p} \\ f_{b}=f_{\mathrm{e}}, \theta_{p}>0.85 \theta_{c p}\end{array}\right.$

where, $\theta_{c p}$ is volume fraction of compacted particles; $f_{w}$ and $f_{e}$ are obtained from models Wen-Yu and Ergun.

In collision of computational particles, following equation of particle normal stress is adopted:

$$
\tau_{p}=\frac{P_{s} \theta_{p}^{\gamma}}{\max \left[\left(\theta_{c p}-\theta_{p}\right), \varepsilon\left(1-\theta_{p}\right)\right]}
$$

where, $P_{s}$ is a constant greater than zero; $\gamma$ is own coefficient of the model, $[1.2,5] ; \varepsilon$ is a small quantity built to eliminate singular points from the model.

\section{COMPUTATIONAL CONDITIONS}

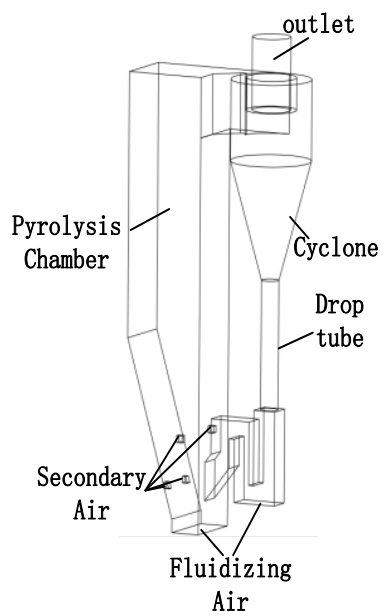

Figure 1. Structure of oil shale pyrolysis circulating fluidized bed

Oil shale particles carried by flue gas is fluidized and pyrolyzed in pyrolysis chamber, producing oil gas and useless shale particles that are discharged from cyclone separator outlet. Oil shale particles produced through incomplete pyrolysis have large mass and is returned by cyclone separator to pyrolysis chamber to participate in pyrolysis. The device is cladded in heating unit that stabilizes internal temperature, so the fluidization degree of oil shale particles is critical to pyrolysis. However, the fluidization conditions of pyrolysis chamber and the separation efficiency of cyclone separator are affected by main-flow air intake (fluidized air velocity).

In order to reduce computation, leave out the heating structure outside CFB. Figure 1 shows pyrolysis CFB, composed of pyrolysis chamber and cyclone separator. There are two fluidized air inlets at the bottom of CFB. There are four secondary airflow inlets on the wall of pyrolysis chamber. Secondary airflow sends oil shale particles to pyrolysis chamber. The feed quantity is $0.625 \mathrm{t} / \mathrm{h}$, and the secondary airflow intake is $17.46 \mathrm{t} / \mathrm{h}$. Fluidized air under cyclone separator is intended to improve the circulation of recycled oil shale particles entering pyrolysis chamber. At that position, the fluidization gas velocity is $2.34 \mathrm{t} / \mathrm{h}$. Fluidized air under pyrolysis chamber is the main power driving fluidization. Therefore, this paper discusses the fluidization of oil shale particles at three different main-flow fluidized air velocities: $36 \mathrm{t} / \mathrm{h}, 49 \mathrm{t} / \mathrm{h}$ and $54 \mathrm{t} / \mathrm{h}$.

Since this paper focuses on the particle fluidization process and takes cold-state CFB as the computational object, temperature-dependent changes in surface viscosity are ignored. The density of oil shale particles is $1,750 \mathrm{~kg} / \mathrm{m}^{3}$, and the regularity of particle size distribution is set to $60 \mu \mathrm{m} \sim 2$ $\mathrm{mm}$ normal distribution.

\section{RESULT ANALYSIS}
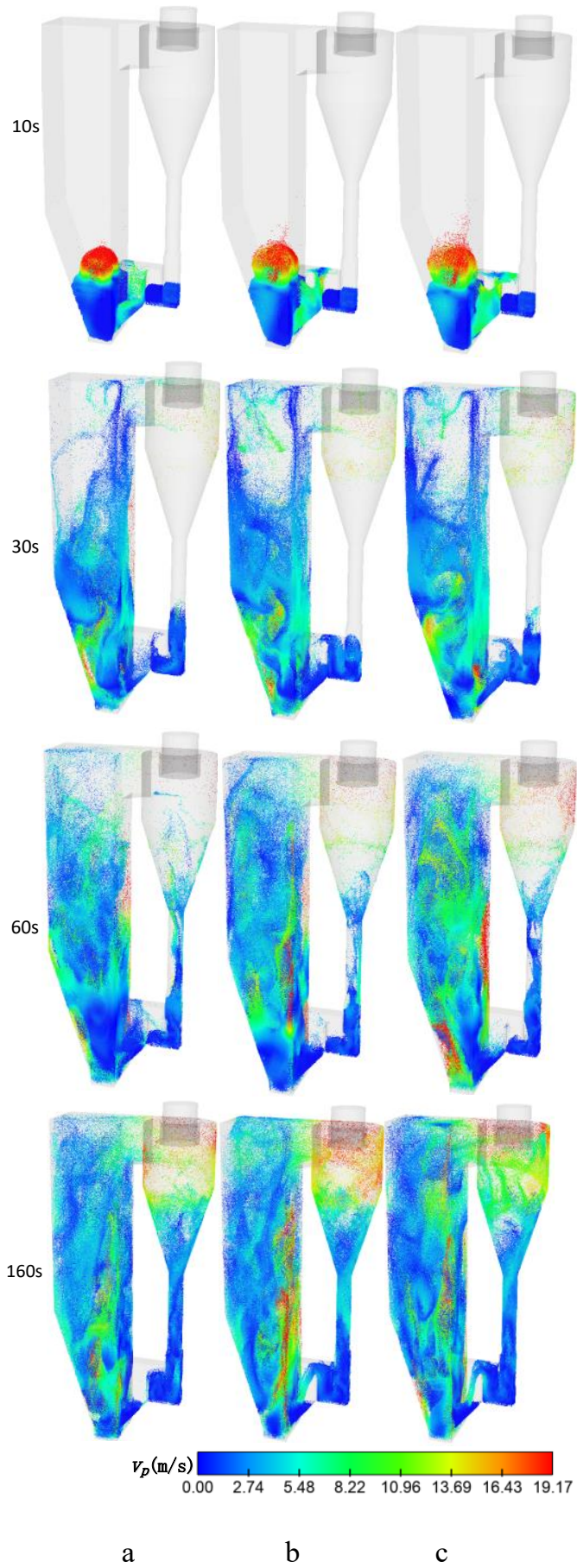

Figure 2. Particle flow at varying main-flow air intake 
Figures 2(a), (b), and (c) show the particle fluidization at varying main-flow air intake: $36 \mathrm{t} / \mathrm{h}, 49 \mathrm{t} / \mathrm{h}$, and $54 \mathrm{t} / \mathrm{h}$. It can be seen that: when main-flow gas just enters pyrolysis chamber, a spherical zone bulges at the center of oil shale particles, and particles flow fast here. As more mainstream gas gets in the chamber, the bulge starts bursting, and the internal particle field starts being fluidized. The greater the inlet main-flow air intake is, the shorter it is before the bulge bursts. At the same time, particles in pyrolysis zone can enter cyclone separator more quickly. However, the particle fluidization result at $160 \mathrm{~s}$ suggests that: when main-flow air intake is $49 \mathrm{t} / \mathrm{h}$ particles enter cyclone separator more quickly than that in the other 2 cases; when main-flow air intake is $54 \mathrm{t} / \mathrm{h}$, the quantity of particles entering cyclone separator simultaneously is large.
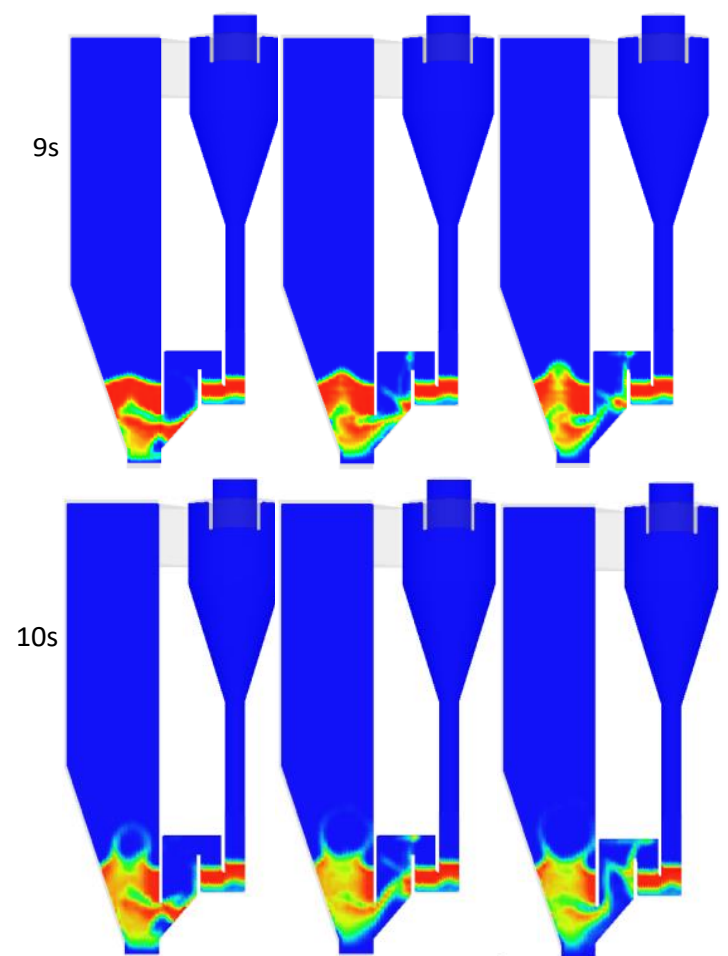

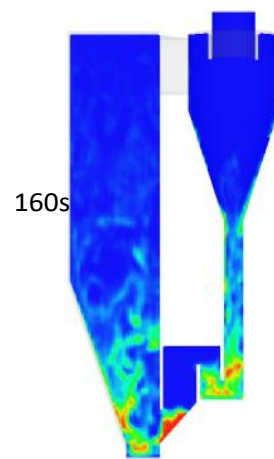

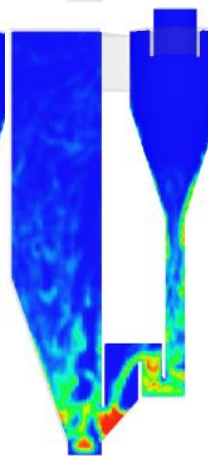

b

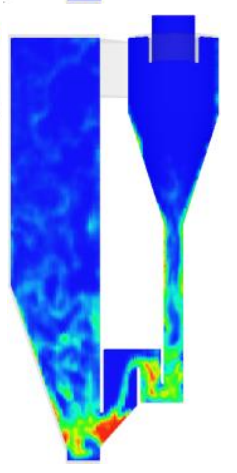

c
Figure 3. Distribution of particles volume fraction

Figures 3(a), (b), and (c) show the particle volume fraction on a vertical central cross section at varying main-flow air intake: $36 \mathrm{t} / \mathrm{h}, 49 \mathrm{t} / \mathrm{h}$, and $54 \mathrm{t} / \mathrm{h}$. It can be seen that particles move to different positions over time, but a high-concentration particle zone is always under the pyrolysis zone. As main-flow air intake rises, the change in particle concentration distribution is not obvious. However, the higher main-flow air intake is, the shorter it is before particles reach fluidization stability.
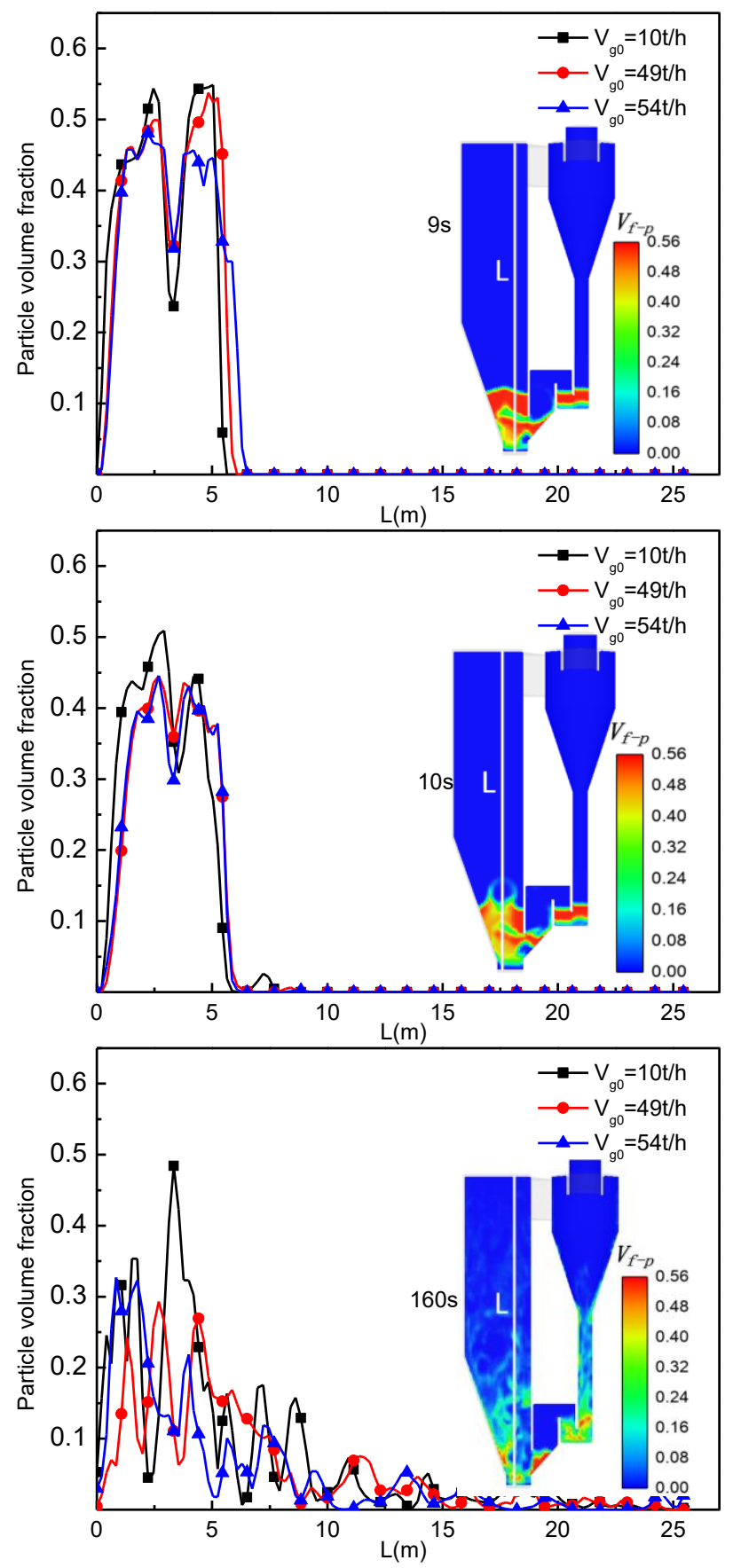

Figure 4. Change of volume fraction on sampling line (vertically)

A "bubble" bulge zone exists during fluidization, and its destruction time is critical to judging whether the internal flow field starts fluidization or not. Make a data analysis along Zaxis direction based on this "bubble" center. The corresponding change of particle volume fraction is shown in Figure 4. Since this zone, similar to bubble phenomenon, forms by gas gathering, the volume fraction of oil shale particles is small. From Figure 4, we can find that: the bubble starts to form at 9s; the larger main-flow air intake is, the more rapidly the bubble moves up. Over time the bulge zone bursts and particles start instable flowing, so the particle volume fraction along sampling line fluctuates wildly in late stage. The volume fraction gets smaller and smaller when approaching the top of pyrolysis chamber, so the structure height can be reduced in later transformation. 

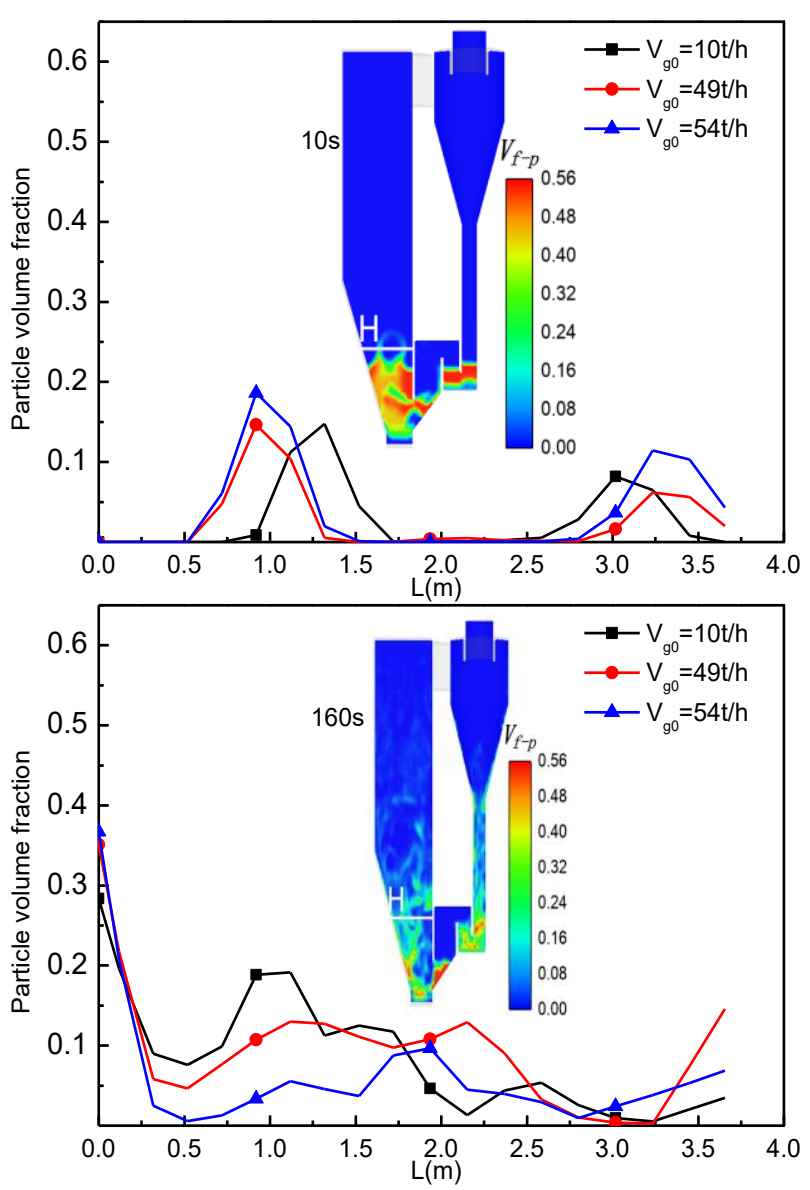

Figure 5. Change of volume fraction on sampling line (horizontally)

As a result of different mass and flow rate of main flow, the volume of gas gathering at "bubble" zone in a unit of time varies, and the horizontal size of "bubble" changes too. In order to analyze the horizontal change of "bubble", we arrange a horizontal sampling line at the side of pyrolysis chamber. This sampling line passes the center of bubble. Since the particle volume fraction is small inside bubble, the horizontal size of "bubble" depends on the volume fraction at the boundary of bubble, i.e. horizontal distance between two adjacent peaks in change curve, as shown in Figure 5. It can be seen that: at $10 \mathrm{~s}$, the horizontal size of "bubble" is about $1.7 \mathrm{~m}$ where air intake is $36 \mathrm{t} / \mathrm{h}$; the horizontal size of "bubble" is subtly different and more than $1.7 \mathrm{~m}$, where air intake is $49 \mathrm{t} / \mathrm{h}$ or $54 \mathrm{t} / \mathrm{h}$. Combined with Figure 3, we can find that: at $10 \mathrm{~s}$, "bubble" has broken where air intake is $49 \mathrm{t} / \mathrm{h}$ or $54 \mathrm{t} / \mathrm{h}$. The horizontal size at burst is little affected by main-flow air intake. When internal particles are completely fluidized, the particle volume fraction on horizontal sampling line basically fluctuates around one value. However, as air intake increases, the particle volume fraction at the bottom of pyrolysis chamber decreases.

At varying main-flow air intake, the distribution of internal airflow velocity on vertical central cross section is shown in Figure 6, where points (a), (b) and (c) correspond to the fluidized air intake: $36 \mathrm{t} / \mathrm{h}, 49 \mathrm{t} / \mathrm{h}$, and $54 \mathrm{t} / \mathrm{h}$ respectively. It can be seen that: when fluidization is stable, the outlet gas velocity rises as air intake increases. When air intake increases to a certain value, the local flow velocity inside pyrolysis chamber decreases.

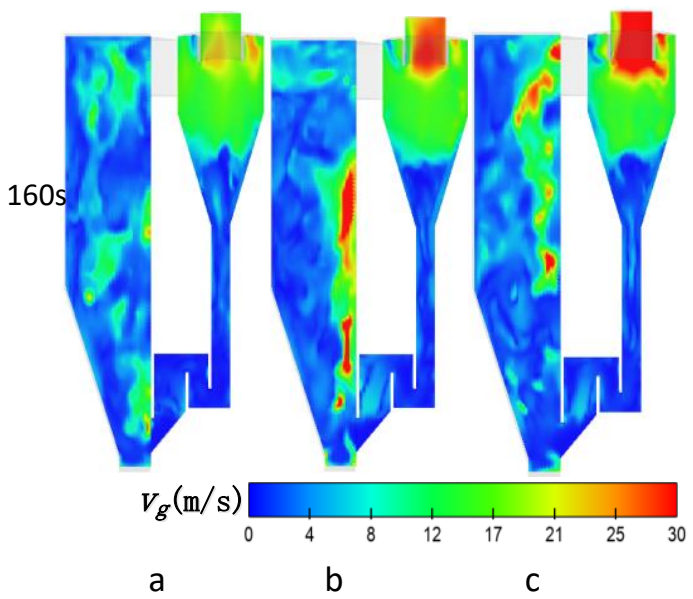

Figure 6. Distribution of airflow velocity field

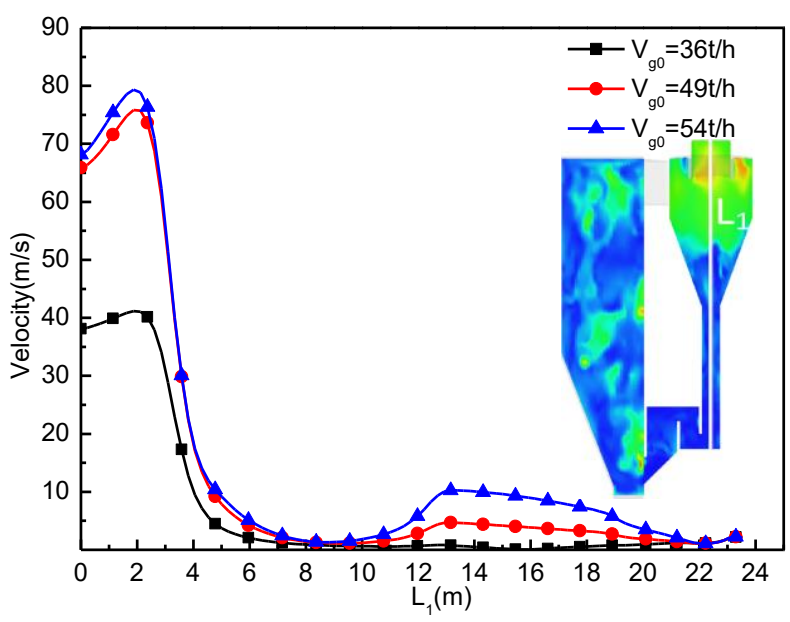

Figure 7. Change of velocity on the center line of cyclone separator

According to Figure 6, increasing the air intake in pyrolysis zone will influence the airflow motion inside cyclone separator. From the velocity change on the vertical center line of cyclone separator, shown in Figure 7, we can know that: as air intake rises, the air-flow velocity at cylinder end of cyclone separator increases significantly, and the air-flow velocity at conic section and drop tube increases little. Combined with Figure 2, it is obvious that the particle velocity is high in these high airflow velocity zones. In Figure 2, the particle velocity at air intake of $49 \mathrm{t} / \mathrm{h}$ is higher than that at air intake of $54 \mathrm{t} / \mathrm{h}$; but in Figure 7 , the airflow velocity at air intake of $49 \mathrm{t} / \mathrm{h}$ is lower than that at air intake of $54 \mathrm{t} / \mathrm{h}$. This is because the fluid flows slowly near walls. Increasing main-flow air intake may improve the flow velocity of entering cyclone separator and make particles inside cyclone separator move close to walls. Therefore, the changes of airflow velocity and particle velocity are different.

Figure 8 shows the pressure distribution on vertical central cross section at time points $10 \mathrm{~s}$ and 160 s corresponding to varying air intake. It can be seen that: before fluidization, particles block airflow and stop the release of air pressure, causing a high air pressure in particle accumulation zones. With fluidization, particles diffuse and do not block airflow as much as before. Then, the air pressure drops in these zones. 


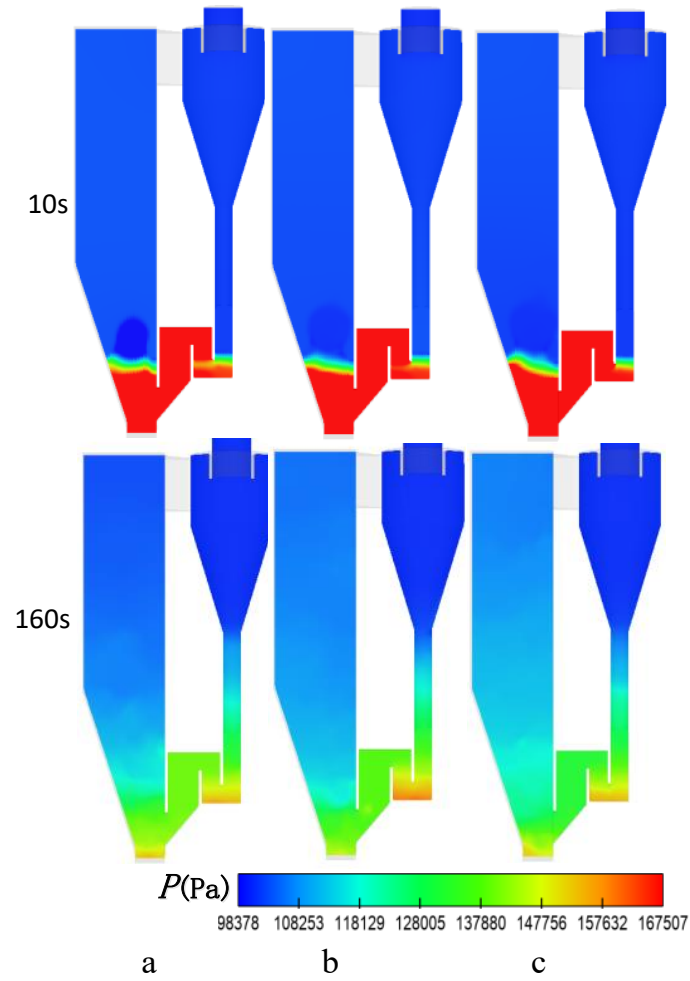

Figure 8. Pressure Distribution
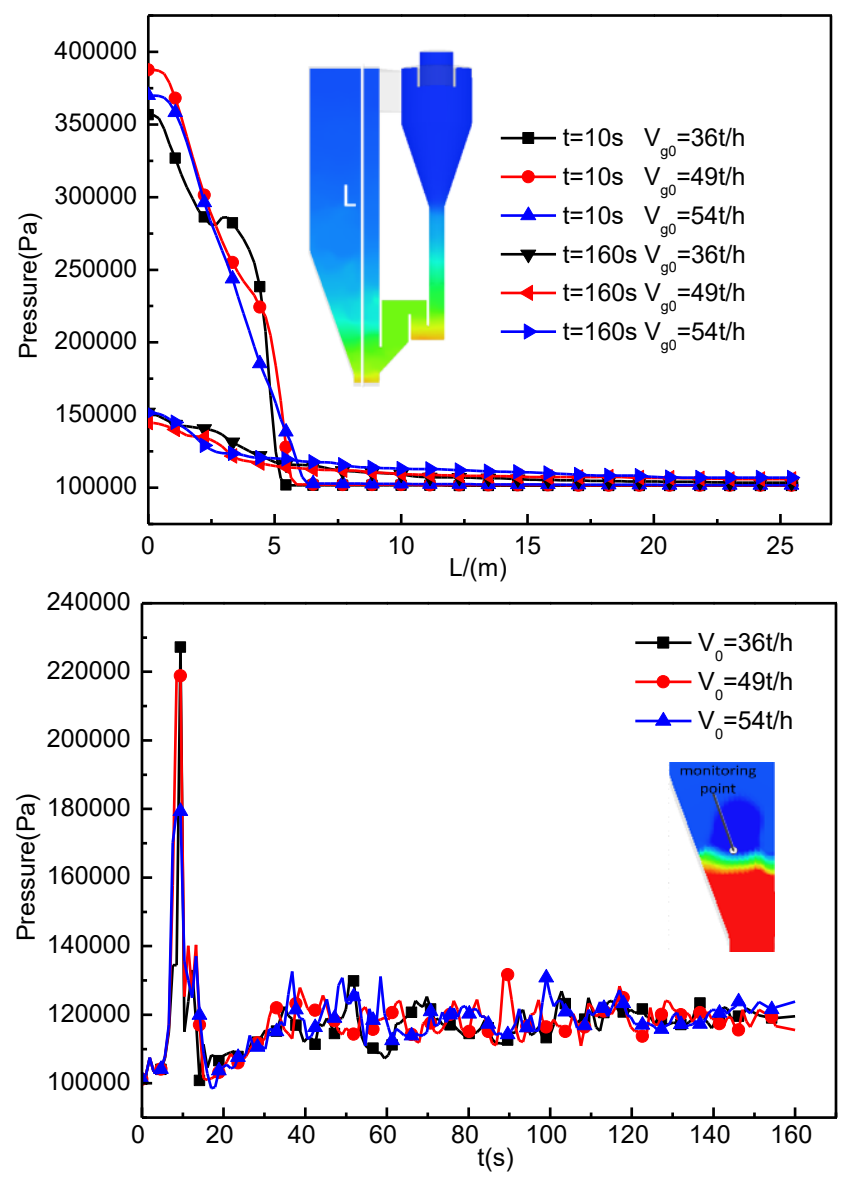

Figure 9. Pressure distribution

In Figure 8, it can be seen from the pressure nephogram at 10 s that a low pressure zone exists at the center of pyrolysis chamber and is near "bubble". Select a pressure test point from the center of oil shale particles accumulation face, and Figure 9 shows the pressure change during fluidization at this point. It can be found that: the larger air intake is, the lower the pressure peak at this point is. A pressure peak occurs mostly because bubble moves up and finally bursts. When fluidization gets stable, the pressure change is basically stable.

\section{CONCLUSIONS}

This paper takes oil shale pyrolysis fluidized bed as the research object and discusses the influence of varying fluidized air intake on the particles fluidization process based on CPFD method. The analysis results are given below:

(1) At the beginning of fluidization, a spherical "bubble" phenomenon occurs in the oil shale particles accumulation zone at the bottom of pyrolysis chamber. When the "bubble" bursts, the horizontal size is subtly affected by fluidized air intake.

(2) The larger fluidized air intake is, the shorter it is before the "bubble" bursts and the shorter it is too before fluidization gets stable.

(3) Increasing fluidized air intake may improve the cyclone separator outlet air velocity and the fluidization at the bottom of pyrolysis chamber.

\section{REFERENCES}

[1] Zhao X, Liu Z, Liu Q. (2017). The bond cleavage and radical coupling during pyrolysis of Huadian oil shale. Fuel 199: https://doi.org/10.1016/j.fuel.2017.02.095

[2] Jiang HB, Zhu ZP, Wang Y, Yu KS, Liu JP. (2014). Pyrolysis characteristics for oil extraction of pulverized Yaojie oil shale in bubble column reactor. Chemical Enginee Ring 42(10): 15-19. https://doi.org/10.3969/j.issn.1005-9954.2014.10.004

[3] Chang Z, Chu M, Zhang C, Bai S, Lin H, Ma LB. (2018). Influence of inherent mineral matrix on the product yield and characterization from Huadian oil shale pyrolysis. Journal of Analytical \& Applied Pyrolysis 130: 269-276. https://doi.org/10.1016/j.jaap.2017.12.022

[4] Gagliano A, Nocera F, Patania F, Bruno M, Scirè S. (2016). Kinetic of the pyrolysis process of peach and apricot pits by TGA and DTGA analysis. International Journal of Heat and Technology 34(2): S553-S560. https://doi.org/10.18280/ijht.34Sp0250.

[5] Soone J, Doilov S. (2003). Sustainable utilization of oil shale resources and comparison of contemporary technologies used for oil shale processing. Oil Shale 20(3): 311-323.

[6] Potapov OP, Khaskhachikh VV, Gerasimov GY. (2017). State-of-the-art technologies of oil shale thermal processing. Journal of Physics Conference Series 891(1): 012236. https://doi.org/10.1088/17426596/891/1/012236

[7] Qin H, Yue YK, Liu HP, Wang Q. (2015). Current status and prospect of oil shale retorting technologies in China. Chemical Industry and Engineering Progress 34(5): 1191-1198.

[8] Pan Y, Zhang X, Liu S, Yang S, Ren N. (2012). A review on technologies for oil shale surface retort. JournalChemical Society of Pakistan 34(6): 1331-1338.

[9] Gao M, Hong F, Liu J. (2017). Investigation on energy storage and quick load change control of subcritical circulating fluidized bed boiler units. Applied Energy 
185(1):

463-471

https://doi.org/10.1016/j.apenergy.2016.10.140

[10] Lyu J, Yang H, Ling W, Nie L, Yue G, Wang SL. (2017). Development of a supercritical and an ultra-supercritical circulating fluidized bed boiler. Frontiers in Energy (4): 1-6. https://doi.org/10.1007/s11708-017-0512-4

[11] Palkar RR, Shilapuram V. (2017). Artificial Neural Network Modeling of Hydrodynamics of Liquid-Solid Circulating Fluidized Beds. Chemical Engineering \& Technology 40(1): 145-152.

[12] Guo QJ, Qi XN, Wei Z, Yang BB, Sun P. (2016). Experimental study on hydrodynamic performance and heat transfer mechanism of vapor-liquid-solid threephase fluidized bed. International Journal of Heat and Technology 34(3):

$537-544$ https://doi.org/10.18280/ijht.340327

[13] Snider DM. (2001). An incompressible three dimensional multiphase particle-in-cell model for dense particle flows. Journal of computational physics 170(2): 523-549. https://doi.org/10.1006/jcph.2001.6747

[14] Qiu GZ, Ye JM, Wang HG, Wang XF, Wang FJ, Sun YK, Nie L. (2016). CPFD simulation of gas-solids flow in annular combustion chamber of large-scale circulating fluidized bed. Journal of University of Chinese Academy of Sciences 33(2): 18-222.

[15] Amarasinghe WS, Jayarathna CK, Ahangama BS, Moldestad BME, Tokheim LA. (2017). Experimental study and CFD modelling of minimum fluidization velocity for geldart A, B and D particles. International Journal of Modeling \& Optimization, 7(3): 152-156. https://doi.org/10.7763/IJMO.2017.V7.575

[16] Chladek J, Jayarathna CK, Moldestad BME, et al. (2018). Fluidized bed classification of particles of different size and density. Chemical Engineering Science 177: 151162. https://doi.org/10.1016/j.ces.2017.11.042 